\title{
Effects of Hemorrhage on Regional Blood Flow Distribution in Dogs and Primates
}

\author{
STEPHEN F. VATNER \\ From the Departments of Medicine, Harvard Medical School and Peter Bent \\ Brigham Hospital, and the Department of Cardiology, Children's Hospital \\ Medical Center, Boston, Massachusetts 02115
}

\begin{abstract}
A BSTRACT The effects of hemorrhage on arterial pressure, blood flows, and resistances in the coronary, mesenteric, renal, and iliac beds of healthy, conscious dogs and intact, tranquilized baboons were studied. Mild nonhypotensive hemorrhage $(14 \pm 2 \mathrm{ml} / \mathrm{kg})$ increased heart rate and mesenteric and iliac resistances slightly but significantly, and decreased renal resistance $(-13 \pm$ $2 \%$ ). Moderate hypotensive hemorrhage, $26 \pm 2 \mathrm{ml} / \mathrm{kg}$, reduced mean arterial pressure $(-23 \pm 2 \mathrm{~mm} \mathrm{Hg})$ and blood flows to the mesenteric $(-56 \pm 3 \%)$, iliac $(-58 \pm$ $5 \%)$, and coronary $(-39 \pm 4 \%)$ vascular beds, and increased heart rate $(+89 \pm 9$ beats $/ \mathrm{min})$ and resistances in the mesenteric $(+73 \pm 15 \%)$, iliac $(+102 \pm 19 \%)$, and coronary $(+27 \pm 5 \%)$ beds. In contrast to the other beds, renal flow rose $11 \pm 6 \%$ above control and renal resistance fell $31 \pm 2 \%$ below control. Renal vasodilatation with hemorrhage was also observed in five baboons. The increases in mesenteric and iliac resistances were blocked almost completely by phentolamine, while the increase in coronary resistance was only partially blocked by phentolamine. The renal dilatation was not blocked by phentolamine, propranolol, atropine, or tripelennamine, but was prevented by indomethacin, suggesting that this dilatation was mediated by a prostaglandin-like compound.
\end{abstract}

Thus the peripheral vascular responses to hemorrhage involve intense vasoconstriction in the mesenteric and iliac beds. In the normal conscious dog and the intact, tranquilized primate, the renal bed does not share in the augmentation of total peripheral resistance with nonhypotensive and moderate hypotensive hemorrhage, but does with more severe hemorrhage. In fact, renal

This study was presented in part at the fall meeting of the American Physiological Society, 21 August, 1973 in Rochester, N. Y.

Dr. Vatner is an Established Investigator of the American Heart Association.

Received for publication 6 September 1973 and in revised form 9 November 1973. vasodilatation occurs with nonhypotensive or moderate hypotensive hemorrhage, which can be prevented by blockade of prostaglandin synthetase with indomethacin.

\section{INTRODUCTION}

One of the primary reflex adjustments to hemorrhage involves intense peripheral vasoconstriction $(1,2)$. The augmentation of peripheral vascular resistance is thought to be shared primarily by the renal, mesenteric, and muscle beds $(1,2)$. These concepts of reflex circulatory responses to hemorrhage have been derived primarily from studies in anesthetized animals or conscious man and animals utilizing indirect or intermittent techniques for measuring blood flow $(1,2)$. Since the response to hemorrhage is a continuously evolving function, which cannot be described adequately by one measurement at one or a few instants in time, and since anesthesia alters vascular tone in the peripheral beds $(3,4)$ and in particular reflex control of the circulation $(5,6)$, it appeared important to study instantaneous and continuous responses to hemorrhage in conscious animals in which all control mechanisms are intact and the complicating influences of anesthesia and acute surgical manipulation are absent.

Accordingly, the goal of the present investigation was to clarify the peripheral vascular responses to mild and moderate hemorrhage in healthy, conscious, trained dogs and in tranquilized baboons in which arterial pressure and regional blood flows were measured instantaneously and continuously. The specific objectives of this study were to determine $(a)$ the relative roles of the coronary, mesenteric, renal, and iliac beds in the response to hemorrhage, and $(b)$ the efferent mechanisms mediating these changes.

\section{METHODS}

17 normal mongrel dogs $(24-34 \mathrm{~kg})$ were studied in the conscious state. Five baboons (Papio anubis) (24-26 kg), 
tranquilized with phencyclidine hydrochloride, $1 \mathrm{mg} / \mathrm{kg}$, were studied. All operations were conducted under i.v. pentobarbital $\mathrm{Na}, 30 \mathrm{mg} / \mathrm{kg}$. Through a thoracotomy in the fifth left intercostal space, Doppler ultrasonic flow transducers were placed around the left circumflex coronary arteries and stimulator electrodes were sutured to the left ventricles (six dogs). Electromagnetic flow transducers ${ }^{1}$ were implanted around the ascending aortas in four dogs. Through a midline laparotomy, Doppler ultrasonic (seven dogs) or electromagnetic (one $\mathrm{dog}$ ) transducers were placed around the mesenteric, left renal, and left iliac arteries. Two of the eight dogs had both Doppler and electromagnetic flow transducers on the renal artery. Five of these eight dogs were studied before and after splenectomy. Doppler ultrasonic flow probes were also placed around the left renal (five baboons), mesenteric (three baboons), and iliac (three baboons) arteries. In all animals a heparinfilled Tygon catheter was implanted in the aorta to sample arterial pressure, while another Tygon catheter was implanted in the jugular vein for phlebotomy. Five additional dogs were anesthetized with pentobarbital $\mathrm{Na}, 30 \mathrm{mg} / \mathrm{kg}$, and were studied with the abdomen open immediately after placement of the electromagnetic flow transducers ${ }^{1}$ on the left renal artery. All animals were maintained on their respective diets before and after the operation.

Arterial pressure was sampled with the previously implanted heparin-filled Tygon catheter and measured with a Statham P23 Db strain gauge manometer. Regional blood flow was measured with an ultrasonic Doppler flowmeter in seven dogs and five baboons. This system, which has been described in detail previously, has a reliable zero reference $(7,8)$ and in these experiments electrical zero blood flow was determined repeatedly and was confirmed by calibration when the animal was sacrificed. The relationship between velocity, as measured by the Doppler flowmeter, and volume flow is linear as long as the cross-sectional area of the blood vessel within the transducer remains constant. This linear relationship between velocity and volume flow has been demonstrated repeatedly and confirmed by means of timed collections of blood flow (8). At autopsy, it was observed that the vessels were firmly adherent to the flow transducers through a fibrous scar, which minimized changes in the cross-sectional area of the blood vessel within the flow transducers. In six conscious dogs and five anesthetized dogs, an electromagnetic flowmeter ${ }^{1}$ was used to measure blood flow. In the experiments in which regional flows were measured, zero flow was determined by inflating a previously implanted hydraulic occlusive cuff, while in the aortic flow experiments, zero flow was assumed to occur during mid and late diastole.

The experiments were conducted 3 wk- 2 mo after the operation when the dogs and baboons had recovered from operation and were again vigorous and healthy. Control records of cardiac output, regional blood flows, arterial pressure, and heart rate were obtained continuously while the unsedated dogs were resting quietly in the control state as well as during and after hemorrhage. The experiments were conducted without evidence of the animals' arousal or discomfort. In all animals blood was withdrawn from the catheter in the jugular vein until a sustained fall in mean arterial pressure of $20-30 \mathrm{~mm} \mathrm{Hg}$ was attained, while in three dogs and three baboons hemorrhage was continued until a sustained fall of over $40 \mathrm{~mm} \mathrm{Hg}$ occurred. A moderate amount of hemorrhage, i.e., $20-30 \mathrm{~mm}$ $\mathrm{Hg}$ reduction in mean arterial pressure, was chosen for an

${ }^{1}$ Statham Instruments, Inc., Oxnard, Calif. end point because it could be reproduced in all dogs without signs of discomfort or restlessness. The time required to reach this end point averaged $30 \mathrm{~min}$, but ranged from 10 to $60 \mathrm{~min}$. The nonhypotensive hemorrhage was transiently observed during the $10-60$-min period required to attain the moderate hypotensive response. The protocol was repeated on separate days after i.v. pharmacologic blockades, i.e., beta adrenergic blockade with propranolol, $1-2 \mathrm{mg} / \mathrm{kg}$, alpha adrenergic blockade with phentolamine, $1.0-2.0 \mathrm{mg} / \mathrm{kg}$, cholinergic blockade with atropine, $0.1-0.3 \mathrm{mg} / \mathrm{kg}$, histaminergic blockade with tripelennamine, $2-4 \mathrm{mg} / \mathrm{kg}$. In five dogs and three baboons the response to hemorrhage was repeated after prostaglandin synthetase blockade with indomethacin, 4-6 mg/kg. In six dogs in which coronary blood flow was measured, values were also recorded during the control period and after hemorrhage with heart rate maintained constant by electrical stimulation at a frequency of 150 beats/min.

The data were recorded on a multichannel tape recorder and played back on a direct-writing oscillograph. A cardiotachometer, triggered by the signal from the pressure pulse, provided instantaneous and continuous records of heart rate. Electronic resistor-capacitor. filters with 2-s time constants were used to derive mean arterial blood pressure and mean regional blood flows, while a resistor-capacitor filter with an 8-s time constant was used to derive mean aortic flow (cardiac output). Mean regional vascular resistances were calculated as the quotients of mean arterial pressure and regional blood flows, respectively. Mean and late diastolic coronary vascular resistances were calculated as the quotients of mean and late diastolic arterial pressures and coronary blood flows, respectively. Results were compared to pre-hemorrhage control, and changes from control in the different states were compared with the paired $t$ test (9).

\section{RESULTS}

While measurements were recorded continuously during hemorrhage, two points were chosen to compare with control values; the first occurred before a reduction in arterial pressure, which occurred after $14 \pm 2 \mathrm{ml} / \mathrm{kg}$ of hemorrhage and is designated as the mild nonhypotensive hemorrhage response, while the second point was chosen after a sustained $20-30 \mathrm{~mm} \mathrm{Hg}$ reduction in arterial pressure, which required $26 \pm 2 \mathrm{ml} / \mathrm{kg}$ of hemorrhage in the normal conscious dogs; this later response was termed the moderate hypotensive hemorrhage response.

\section{Effects of hemorrhage in normal conscious dogs}

Systemic effects. Mean arterial pressure in all $17 \mathrm{dogs}$ remained relatively constant at $98 \pm 2 \mathrm{~mm} \mathrm{Hg}$ through the mild hemorrhage response. A sustained decrease in mean arterial pressure, averaging $23 \pm 1 \mathrm{~mm} \mathrm{Hg}$, occurred at $26 \pm 2 \mathrm{ml} / \mathrm{kg}$.

Heart rate increased slightly from $75 \pm 3$ to $92 \pm 4$ beats/min $(P<0.01)$ before arterial pressure fell, and then reached a -maximum of $164 \pm 6$ beats $/ \mathrm{min}$ while mean arterial pressure was falling, and was at $118 \pm 5$ beats/min during the moderate hemorrhage response, i.e., during the period of sustained hypotension. 


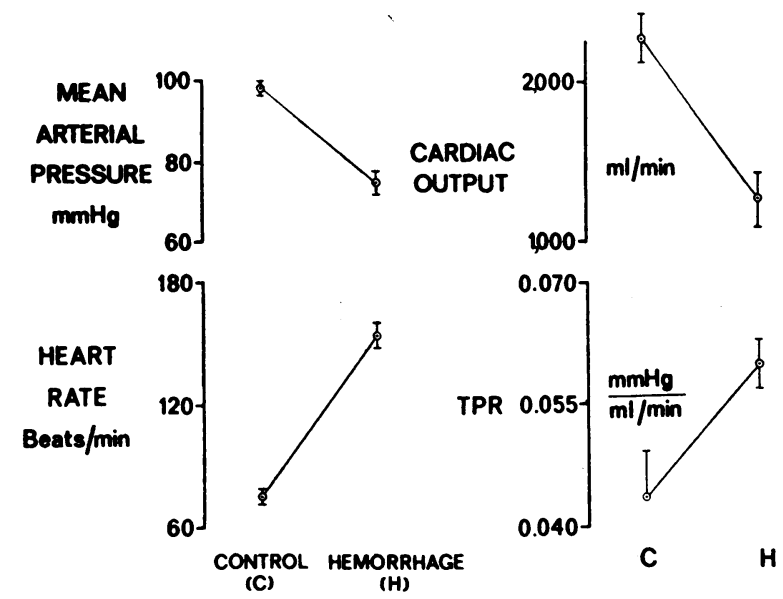

Figure 1 Average \pm SEM maximal effects of moderate hypotensive hemorrhage on mean arterial pressure, heart rate, cardiac output, and total peripheral resistance (TPR).

Cardiac output fell from $2.3 \pm 0.2$ to $2.1 \pm 0.3 \mathrm{liter} / \mathrm{min}$ (NS) during the mild nonhypotensive hemorrhage response and then gradually fell to $1.3 \pm 0.3 \mathrm{liter} / \mathrm{min}$ with moderate hypotensive hemorrhage, while total peripheral resistance rose from a control of $0.044 \pm 0.006$ to $0.059 \pm$ $0.004 \mathrm{~mm} \mathrm{Hg} / \mathrm{ml} / \mathrm{min}$ at the point of sustained hypotension (Fig. 1).

Coronary bed. Mean left circumflex coronary blood flow rose slightly $(+17 \pm 3 \%)(P<0.05)$ and transiently above a control of $38 \pm 3 \mathrm{ml} / \mathrm{min}$ during the mild nonhypotensive hemorrhage response and then fell by $39 \pm 4 \%(P<0.01)$ below control during sustained hypotension; at this point, i.e., during the moderate hypotensive response, mean coronary vascular resistance had increased from $2.65 \pm 0.14$ to $3.38 \pm 0.21 \mathrm{~mm} \mathrm{Hg} / \mathrm{ml} / \mathrm{min}$ $(P<0.01)$. When heart rate was maintained constant by electrical stimulation at a frequency of 150 beats/ min during control and sustained hemorrhagic hypotension, during hemorrhage, mean left circumflex coronary flow fell by $47 \pm 4 \%$ from a control of $49 \pm 4 \mathrm{ml} / \mathrm{min}(P<$ $0.01)$ and mean coronary vascular resistance rose from $2.10 \pm 0.12$ to $3.06 \pm 0.19 \mathrm{~mm} \mathrm{Hg} / \mathrm{ml} / \mathrm{min} \quad(P<0.01)$. The changes in late diastolic coronary flow and resistance paralleled the mean values.

Mesenteric and iliac beds (eight dogs). The mesenteric and iliac beds responded similarly to hemorrhage (Fig. 2). Mesenteric and iliac flows fell from control values of $305 \pm 16$ and $113 \pm 6 \mathrm{ml} / \mathrm{min}$ to $256 \pm 13$ and $90 \pm 6 \mathrm{ml} / \mathrm{min}$, respectively, during the mild nonhypotensive hemorrhage response, and declined to lower levels during the moderate hypotensive hemorrhage response. At that point, mesenteric flow had decreased by $56 \pm 3 \%$ to $136 \pm 13 \mathrm{ml} / \mathrm{min}$ and resistance had increased from $0.33 \pm 0.02$ to $0.59 \pm 0.06 \mathrm{~mm} \mathrm{Hg} / \mathrm{ml} / \mathrm{min}$, while iliac flow had fallen by $58 \pm 5 \%$ to $46 \pm 4 \mathrm{ml} / \mathrm{min}$ and iliac resistance had risen from $0.88 \pm 0.05$ to $1.72 \pm 0.11$ $\mathrm{mm} \mathrm{Hg} / \mathrm{ml} / \mathrm{min}$. These changes were all significant $(P<0.01)$ (Fig. 3). When the changes for flow or resistance in the mesenteric and iliac beds were compared
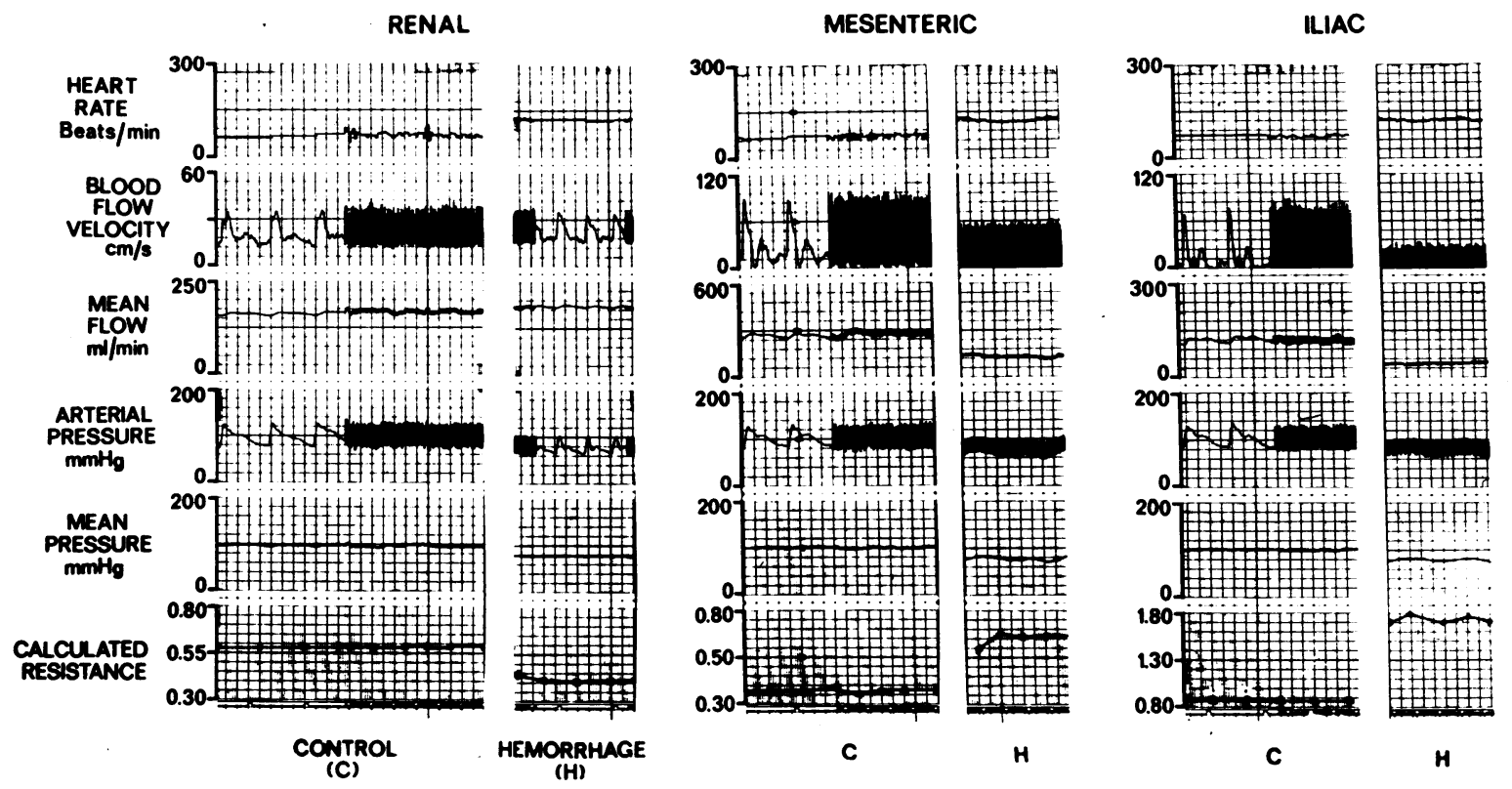

Figure 2 Typical responses of renal, mesenteric, and iliac beds to moderate hypotensive hemorrhage, $26 \mathrm{ml} / \mathrm{kg}$. Responses of heart rate, phasic and mean blood flows, arterial pressures, and calculated mean vascular resistances are shown. In the normal conscious dog, intense mesenteric and iliac vasoconstriction occurred, while the renal bed dilated. 


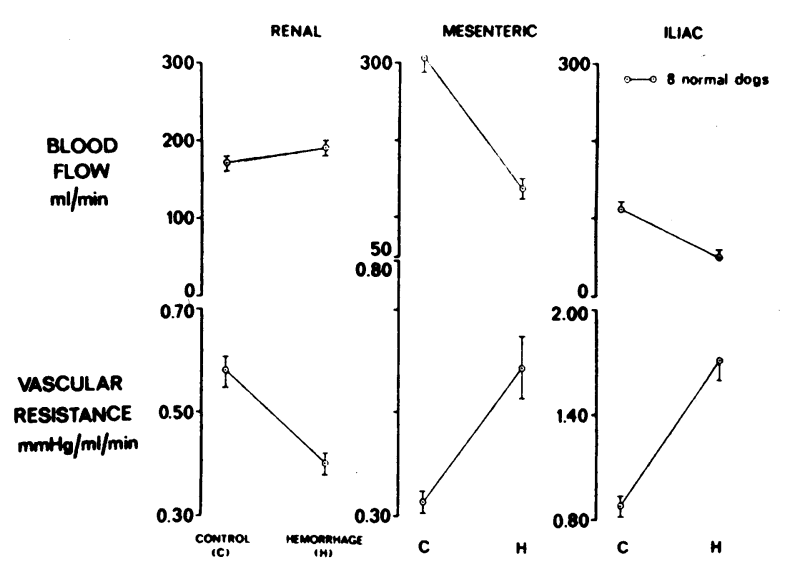

Figure 3 Average \pm SEM values during control and after moderate hypotensive hemorrhage (mean arterial pressure reduction of $20-30 \mathrm{mmHg}$ ) of renal, mesenteric, and iliac beds.

as percent change from control, the responses for these beds with moderate hemorrhage were not significantly different.

Five of these dogs were restudied in the conscious state after recovery from splenectomy. A sustained reduction in mean arterial pressure, averaging $24 \pm 2 \mathrm{~mm}$ $\mathrm{Hg}$, occurred after withdrawal of significantly less $(P<$ 0.01 ) blood, $17 \pm 2 \mathrm{ml} / \mathrm{kg}$, as compared to $26 \pm 2$ required before splenectomy; the smaller amount of hemorrhage required reflects the reservoir function of the canine spleen. However, once the same degree of hypotension had been achieved, the alterations in resistances in the mesenteric and iliac beds were not different from those before splenectomy.
Renal bed (eight dogs). In contrast to the responses of the mesenteric and iliac beds during the nonhypotensive hemorrhage response, renal blood flow increased $15 \pm 4 \%(P<0.05)$ above a control of $173 \pm 8 \mathrm{ml} / \mathrm{min}$ and resistance decreased by $13 \pm 2 \%(P<0.05)$ from a control of $0.58 \pm 0.03 \mathrm{~mm} \mathrm{Hg} / \mathrm{ml} / \mathrm{min}$ (Table I). During the moderate hypotensive hemorrhage response renal flow was slightly $(11 \pm 6 \%)$ (NS) above control and renal resistance was at $0.40 \pm 0.02 \mathrm{~mm} \mathrm{Hg} / \mathrm{ml} / \mathrm{min}$, which was $31 \pm 2 \%(P<0.01)$ below control (Fig. 3). At no time during hemorrhage, when arterial pressure was maintained, or with reductions of pressure of 20-30 $\mathrm{mm} \mathrm{Hg}$, or during the reinfusion of the shed blood, was renal resistance above control levels. The reductions of calculated renal resistance were observed when renal flow was masured with both the Doppler and electromagnetic flowmeters and regardless of the rate of withdrawal of blood (10 min $-1 \mathrm{~h})$.

Five dogs in which renal blood flow was measured were restudied after recovery from splenectomy. As before splenectomy, when arterial pressure fell from $96 \pm 4$ to $72 \pm 4 \mathrm{~mm} \mathrm{Hg}$, renal flow did not fall and calculated renal vascular resistance decreased $27 \pm 3 \%$ from a control of $0.61 \pm 0.05 \mathrm{~mm} \mathrm{Hg} / \mathrm{ml} / \mathrm{min}$.

To determine whether renal vasoconstriction would occur with more severe hemorrhage, in three dogs the renal vascular response to severe hemorrhage was examined by continuing withdrawal of blood after the moderate hypotensive hemorrhage response in which the fall in arterial pressure of $20-30 \mathrm{~mm} \mathrm{Hg}$ had been sustained. When hemorrhage reached 28,31 , and $35 \mathrm{ml} / \mathrm{kg}$, renal dilatation was no longer observed, i.e., renal vascular resistance returned to control levels and mean ar-

TABLE I.

Renal Vascular Effects of Hemorrhage in Dogs and Primates

\begin{tabular}{|c|c|c|c|}
\hline : & $\begin{array}{c}\text { Mild } \\
\text { nonhypotensive }\end{array}$ & $\begin{array}{c}\text { Moderate } \\
\text { hypotensive }\end{array}$ & $\begin{array}{c}\text { Severe } \\
\text { hypotensive }\end{array}$ \\
\hline \multicolumn{4}{|l|}{ Blood loss, $\mathrm{ml} / \mathrm{kg}$} \\
\hline Dog & $14 \pm 2^{*}$ & $26 \pm 2^{*}$ & $50^{*}$ \\
\hline Baboon & $6 \pm 1^{*}$ & $14 \pm 2^{*}$ & $27^{*}$ \\
\hline \multicolumn{4}{|l|}{$\Delta$ Mean arterial pressure, $\%$} \\
\hline Dog $($ control $=98 \pm 3 \mathrm{~mm} \mathrm{Hg})$ & $-2 \pm 1$ & $-23 \pm 2^{*}$ & $-42^{*}$ \\
\hline Baboon (control $=103 \pm 3 \mathrm{~mm} \mathrm{Hg}$ ) & $-2 \pm 1$ & $-23 \pm 2^{*}$ & $-53^{*}$ \\
\hline \multicolumn{4}{|l|}{$\Delta$ Renal blood flow, $\%$} \\
\hline Dog $($ control $=173 \pm 8 \mathrm{ml} / \mathrm{min})$ & $+15 \pm 4_{+}^{+}$ & $+11 \pm 6$ & $-67 *$ \\
\hline Baboon (control $=150 \pm 5 \mathrm{ml} / \mathrm{min})$ & $+7 \pm 2 \ddagger$ & $-1 \pm 1$ & $-69^{*}$ \\
\hline \multicolumn{4}{|l|}{$\Delta$ Renal resistance, $\%$} \\
\hline Dog $($ control $=0.58 \pm 0.03 \mathrm{~mm} \mathrm{Hg} / \mathrm{ml} / \mathrm{min})$ & $-13 \pm 2 \ddagger$ & $-31 \pm 2 *$ & $+55^{*}$ \\
\hline Baboon (control $=0.68 \pm 0.02 \mathrm{~mm} \mathrm{Hg} / \mathrm{ml} / \mathrm{min}$ ) & $-9 \pm 2 \ddagger$ & $-22 \pm 2^{*}$ & $+51^{*}$ \\
\hline
\end{tabular}

* Significant change from control, $P<0.01$.

‡ Significant change from control, $P<0.05$. 

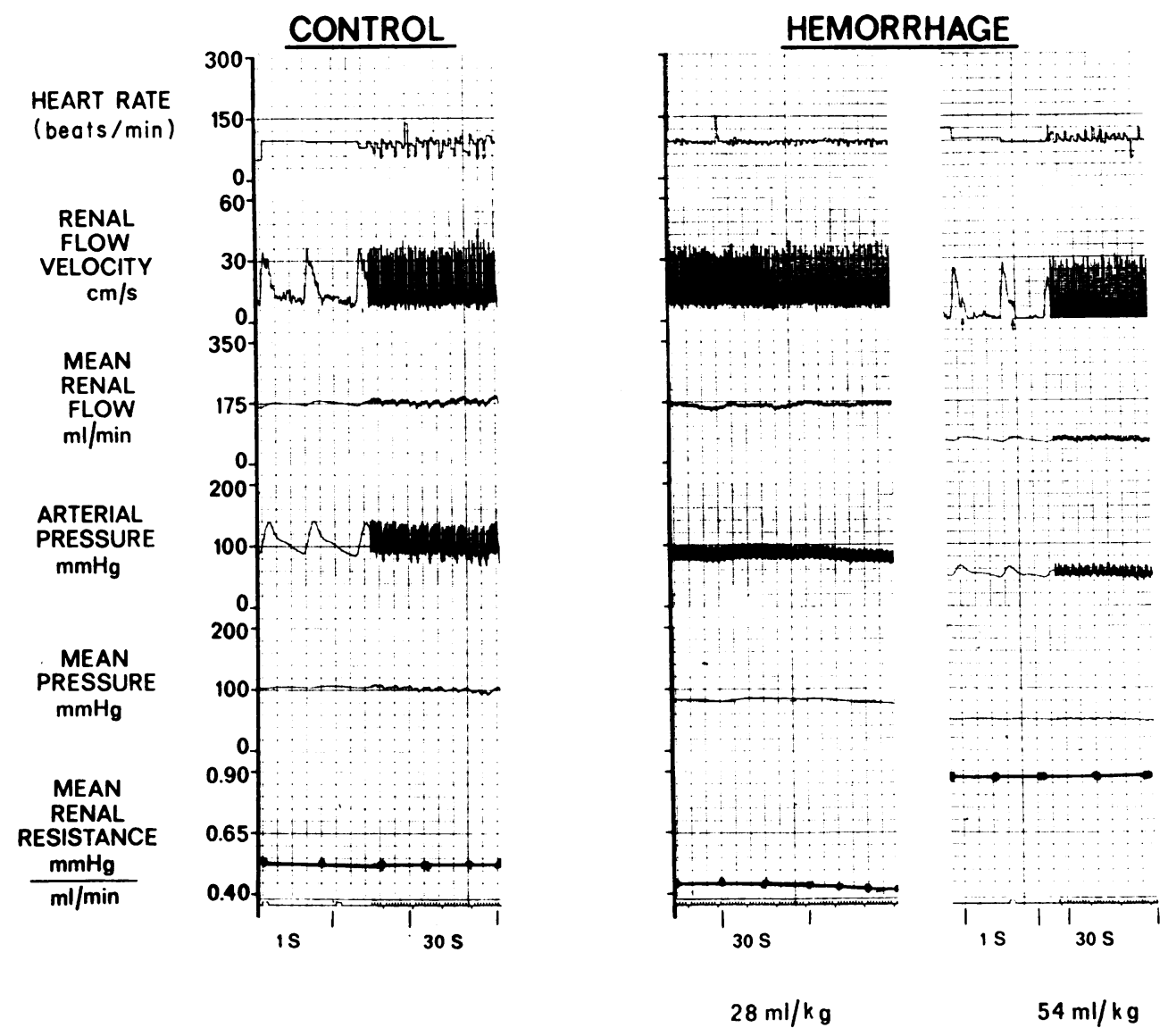

Figure 4 Renal responses to moderate hypotensive hemorrhage (middle panel) and severe hemorrhage (right panel) compared to control (left panel) in a conscious dog. Renal dilatation occurred with moderate hemorrhage, while constriction occurred with severe hemorrhage. The arrows on the phasic renal flow tracings during severe hemorrhage point to occurrence of possible reverse renal flow.

terial pressure remained depressed by an average of 25 $\mathrm{mm} \mathrm{Hg}$, but renal flow fell by an average of $27 \%$ from a prehemorrhage level of $172 \mathrm{ml} / \mathrm{min}$. After $50 \mathrm{ml} / \mathrm{kg}$ had been withdrawn, arterial pressure had declined to an average of $58 \%$ of control, renal flow fell to $33 \%$ of control and renal resistance rose to an average of $55 \%$ above control (Fig. 4).

Effects of blocking agents on regional vascular responses to hemorrhage (five dogs)

Alpha receptor blockade. Phentolamine, $1 \mathrm{mg} / \mathrm{kg}$, increased heart rate from $73 \pm 5$ to $111 \pm 9$ beats $/ \mathrm{min}$ and decreased mean arterial pressure (from $101 \pm 4$ to $90 \pm 4$ $\mathrm{mm} \mathrm{Hg})$, and mesenteric $(-17 \pm 3 \%)$, iliac $(-15 \pm$ $3 \%)$, renal $(-12 \pm 2 \%)$, and coronary $(-11 \pm 2 \%)$ vascular resistances. All of these changes were significant $(P<0.05)$. Only $14 \pm 2 \mathrm{ml} / \mathrm{kg}$ hemorrhage was required to produce a sustained $20-30 \mathrm{~mm} \mathrm{Hg}$ reduction in mean arterial pressure, indicating that the ability of the circulation to withstand hemorrhage was significantly im- paired. At the moderate hypotensive response, the increases in mesenteric $(+22 \pm 5 \%)$ and iliac $(+17 \pm$ $4 \%)$ resistances were significantly less than without blockade $(P<0.01)$. The elevation in coronary vascular resistance with hemorrhage at a constant heart rate $( \pm 0.65 \pm 0.10 \mathrm{~mm} \mathrm{Hg} / \mathrm{ml} / \mathrm{min}$ ) was less after alpha blockade than in the control state $(+0.96 \pm 0.10 \mathrm{~mm} \mathrm{Hg}$ / $\mathrm{ml} / \mathrm{min})(P<0.05)$. However, the reduction in renal resistance $(-29 \pm 3 \%)$ was similar (Table II).

Thus, alpha receptor blockade attenuated the hemorrhage-induced increases in mesenteric and iliac resistances substantially, and coronary resistance slightly, but did not affect the renal vasodilatation.

Other blockades. Beta receptor blockade with propranolol $(1-2 \mathrm{mg} / \mathrm{kg})$, cholinergic blockade with atropine $(0.1-0.3 \mathrm{mg} / \mathrm{kg})$, and histaminergic blockade with tripelennamine $(1-2 \mathrm{mg} / \mathrm{kg})$, did not affect the pattern of differential vasoconstriction observed with hemorrhage at the point of sustained hypotension. After each of these blockades, the increases in mesenteric and iliac resis- 
TABLE II

Effects of Blockades on Renal Response to Hemorrhage in Conscious Dogs

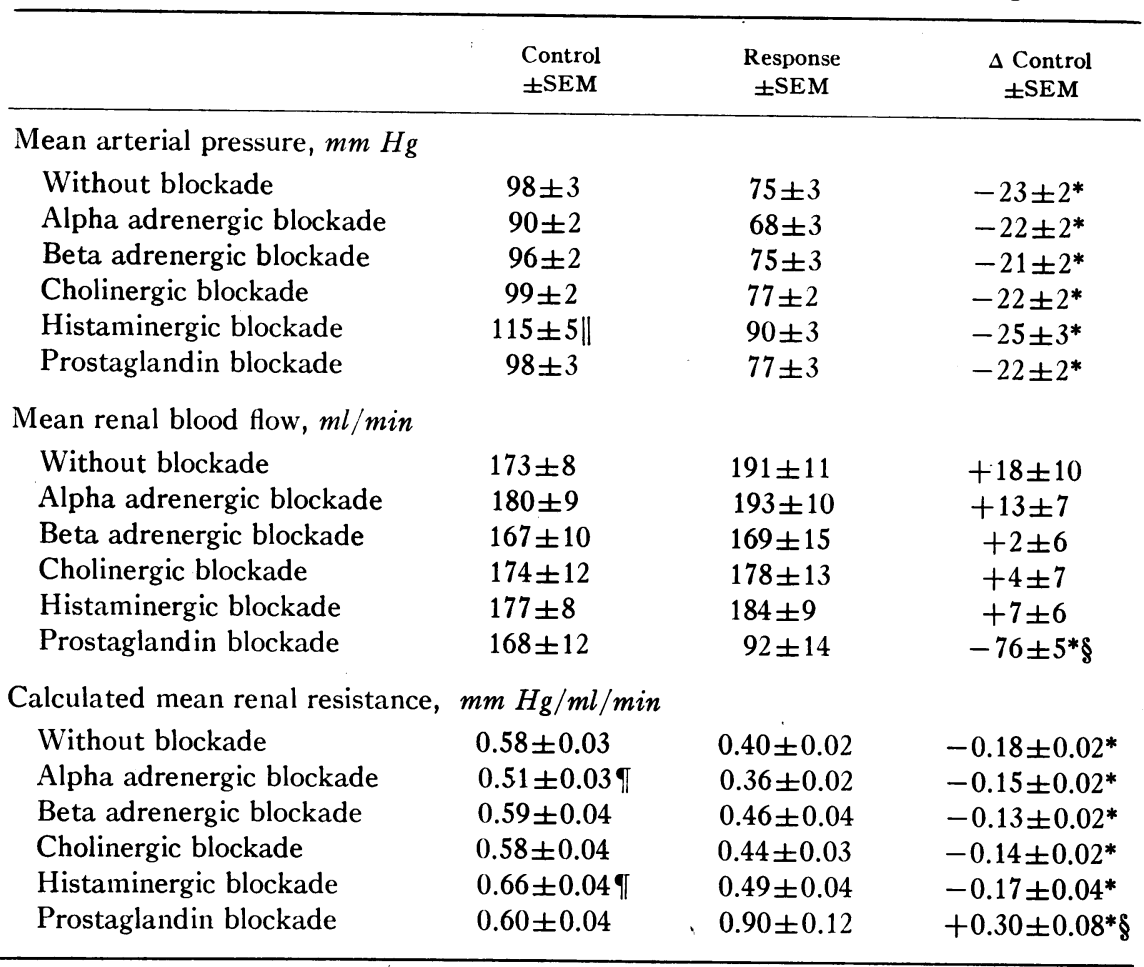

* Significant change from control $P<0.01$.

$\ddagger$ Significant change from control $P<0.05$.

\$ Significantly different from response without blockade $P<0.01$.

\| Significantly different from control value without blockade $P<0.01$.

II Significantly different from control value without blockade $P<0.05$.

tances and reduction in renal resistance with hemorrhage were not significantly different from the responses without blockade (Table II).

Prostaglandin synthetase blockade (five dogs). Indomethacin, 4-6 mg/kg, caused little change in arterial pressure, indicating that indomethacin did not affect significantly the ability of the circulation to withstand hemorrhage. The increases in heart rate, iliac and mesenteric vascular resistance that occurred as a consequence of hemorrhage were not significantly different from those occurring -without indomethacin. However, the response of the renal vascular bed was considerably different. Renal flow not only failed to rise with nonhypotensive hemorrhage, but actually fell slightly $(-16 \pm 3 \%)(P<$ $0.05)$; renal vascular resistance rose at this time $(P<$ $0.05)$. During the period of moderate hypotensive hemorrhage, renal blood flow fell by $45 \pm 5 \%(P<0.01)$ from a control of $168 \pm 12 \mathrm{ml} / \mathrm{min}$, while renal resistance increased by $49 \pm 5 \%(P<0.01)$ from a control of $0.60 \pm$ $0.04 \mathrm{~mm} \mathrm{Hg} / \mathrm{ml} / \mathrm{min}$ (Fig. 5). Thus, indomethacin altered the normal renal response to hemorrhage by reversing the dilatation to sustained constriction.
Combination of blocking agents (three dogs). When blood was withdrawn to reduce mean arterial pressure by 20-30 $\mathrm{mm} \mathrm{Hg}$ after combined alpha and beta receptor, cholinergic and histaminergic blockades renal flow remained essentially at control levels and renal vasodilation occurred with hemorrhage.

\section{Renal vascular response to hemorrhage in primates}

Hemorrhage was induced in five baboons tranquilized with phencyclidine hydrochloride, $1 \mathrm{mg} / \mathrm{kg}$. The mild nonhypotensive hemorrhage response occurred after $6 \pm 1$ $\mathrm{ml} / \mathrm{kg}$ of blood was withdrawn, while $14 \pm 2 \mathrm{ml} / \mathrm{kg}$ of hemorrhage was required to decrease mean arterial pressure by $23 \pm 2 \%$ from a control value of $103 \pm 3 \mathrm{~mm} \mathrm{Hg}$ (Table I). Heart rate rose from $95 \pm 9$ to a maximum of $162 \pm 13$ beats/min just before the moderate hypotensive response. In the three baboons in which mesenteric and iliac blood flows were measured, mild nonhypotensive hemorrhage reduced these flows and increased resistance in these beds by amounts comparable to those in the dogs with nonhypotensive hemorrhage. With moderate hypo- 
tensive hemorrhage, mesenteric and iliac blood flows fell by averages of 46 and $40 \%$, respectively, while resistances in these beds rose by averages of 43 and $35 \%$, respectively.

Renal blood flow rose by $7 \pm 2 \%(P<0.05)$ from a control of $150 \pm 5 \mathrm{ml} / \mathrm{min}$ during the mild nonhypotensive hemorrhage response, while renal resistance fell by $9 \pm 2 \%(P<0.01)$ from a control of $0.68 \pm 0.02 \mathrm{~mm} \mathrm{Hg} /$ $\mathrm{ml} / \mathrm{min}$ (Table I). During the moderate hypotensive response, renal flow was not significantly different from control, but renal resistance had declined by $22 \pm 2 \%$ (Table I). With further hemorrhage averaging $27 \mathrm{ml} / \mathrm{kg}$ carried out in three baboons, renal flow fell by an average of $69 \%$ and renal resistance rose by an average of $51 \%$.

After indomethacin, 4-6 mg/kg, in three baboons, mild nonhypotensive hemorrhage failed to elicit a reduction in renal resistance. During the moderate hypotensive hemorrhage response, when mean arterial pressure had fallen from 108 to $84 \mathrm{~mm} \mathrm{Hg}$, renal flow fell by $43 \%$ and resistance rose by an average of $38 \%$.

Thus, the peripheral vascular response in the tranquilized baboon was like that in the conscious dog. Renal vasodilation, which could be prevented with indomethacin, occurred in both species.

\section{Effects of anesthesia and laparotomy on renal} response to hemorrhage (five dogs)

Pentobarbital, $\mathrm{Na}, 30 \mathrm{mg} / \mathrm{kg}$, followed by surgical implantation of the flow transducer, markedly impaired the ability of the circulation to withstand hemorrhage: only $9 \pm 2 \mathrm{ml} / \mathrm{kg}$ of hemorrhage was necessary to cause a sustained decrease in arterial pressure of $20-30 \mathrm{~mm} \mathrm{Hg}$ from a control value of $102 \pm 4 \mathrm{~mm} \mathrm{Hg}$. At this point renal flow had decreased by $10 \pm 2 \%(P<0.05)$ from a control of $169 \pm 10 \mathrm{ml} / \mathrm{min}$, and renal resistance was $8 \pm 2 \%(P<0.05)$ below a control level of $0.61 \pm 0.04$ $\mathrm{mm} \mathrm{Hg} / \mathrm{ml} / \mathrm{min}$. However, when hemorrhage was continued to $26 \mathrm{ml} / \mathrm{kg}$, renal flow had fallen to $56 \pm 4 \mathrm{ml} /$ min, arterial pressure had fallen to $52 \pm 4 \mathrm{~mm} \mathrm{Hg}$, and renal resistance had risen $(P<0.01)$ to $0.94 \pm 0.08 \mathrm{~mm}$ $\mathrm{Hg} / \mathrm{ml} / \mathrm{min}$.

Thus the response to hemorrhage was affected by anesthesia and laparotomy as follows: much less blood loss was required to effect a $20-30 \mathrm{~mm} \mathrm{Hg}$ decrease in arterial pressure. At that point, a minor degree of renal dilatation $(P<0.05)$ was observed, but when the amount of hemorrhage was similar to that in conscious dogs, intense renal vasoconstriction was observed.

\section{DISCUSSION}

Arterial pressure is maintained during hemorrhage to a large extent through peripheral vasoconstriction (1, 2) induced by increased sympathetic vasoconstrictor tone $(1,2)$, catecholamine secretion $(10,11)$, and renin

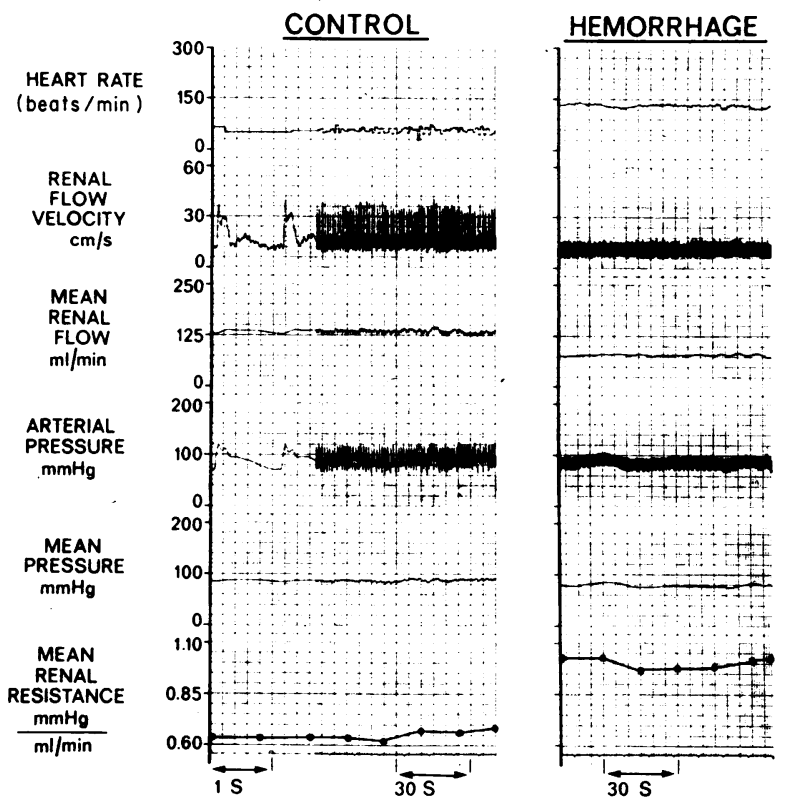

Figure 5 Typical renal response to moderate hypotensive hemorrhage, $25 \mathrm{ml} / \mathrm{kg}$, after pretreatment with indomethacin, $4 \mathrm{mg} / \mathrm{kg}$. This is the response for the same dog as shown without blockade in Fig. 1. Instead of renal dilatation, marked constriction occurred.

release $(10,12)$. The augmentation of total peripheral resistance has been thought to involve the renal, mesenteric, and limb beds $(1,2)$. In the present study, hemorrhage increased total peripheral resistance as expected, but the extent to which the various regional beds participated in this increase in total resistance was variable. Intense reductions of blood flows and increases in resistances occurred in the coronary, mesenteric, and iliac beds; blood flow to the mesenteric and iliac beds fell even with mild hemorrhage, while arterial pressure was still maintained and fell substantially further with moderate hemorrhage. While the mesenteric and iliac vasoconstriction was most likely due predominantly to alpha adrenergic vasoconstriction, the results of the present study suggest that coronary vasoconstriction may have been due to another mechanism, e.g., reduced myocardial oxygen demands, since the coronary resistance also increased with hemorrhage after alpha adrenergic blockade with phentolamine. While some alpha adrenergic coronary vasoconstriction with hemorrhage was apparent in the present study, it appears to play a minor role. Prior studies in anesthetized animals have found coronary vasodilatation predominant with hemorrhage (1316), while one investigation in conscious animals, by Granata, Huvos, Pasque, and Gregg found vasoconstriction predominant, as in the present study (17). These investigators suggested that the increase in coronary resistance was probably a consequence of vasoconstriction mediated by the sympathetic nervous system.

Renal Vasodilation with Hemorrhage 
In contrast to the striking vasoconstrictor responses of the mesenteric and iliac beds, renal flow was well maintained and renal resistance fell with both mild and moderate hemorrhage. Often renal flow rose before pressure fell and renal dilatation persisted even when pressure had declined by $23 \pm 2 \mathrm{~mm} \mathrm{Hg}$. In the baboons as in the dogs, renal dilatation occurred with hemorrhage both before a reduction in arterial pressure and also after a $20-30 \mathrm{~mm} \mathrm{Hg}$ fall in arterial pressure. Thus renal vasodilation occurred in both species. The major difference was the amount of hemorrhage tolerated before arterial pressure fell and required to produce a sustained reduction in arterial pressure, i.e., $14 \pm 2 \mathrm{ml} / \mathrm{kg}$ in the baboons and $26 \pm 2 \mathrm{ml} / \mathrm{kg}$ for the dogs. In contrast, the concept that the renal bed responds to hemorrhage with constriction is widely accepted $(1,2,18-27)$. In fact, there are several studies which indicate the renal bed has the most intense constriction of all peripheral beds studied $(25,26)$.

There are several possible explanations for the discrepancy between the conclusion of previous investigations, indicating intense renal vasoconstriction with hemorrhage (18-27), and those in the present one, demonstrating sparing of the renal bed. Three important features of the present investigation were (a) renal blood flow was measured in the conscious animal, (b) these measurements were instantaneous and continuous, and $(c)$ hemorrhage was not severe or prolonged, i.e., hemorrhagic shock did not develop. Studies indicating intense renal vasoconstriction with hemorrhage were generally conducted in animals after general anesthesia and surgical manipulation of the kidney $(19,20,22,26$, $27)$ or in man and experimental animals utilizing intermittent techniques to measure blood flow $(18,23,25)$. Since the renal response to hemorrhage was found to be qualitatively different with the severity of hemorrhage, it is important to note that prior studies utilizing intermittent techniques generally did not measure renal blood flow before pressure fell or when pressure was reduced only $20-30 \mathrm{~mm} \mathrm{Hg}$, where dilatation was found in the present study. Moreover, in many studies hemorrhage was more intense than in the present investigation.

On the one hand, anesthesia and recent surgical trauma alter regional blood flow distribution $(3,4)$ and reflex control of the circulation $(5,6)$. Thus, it was not surprising that a similar degree of arterial hypotension occurred after $9 \pm 2 \mathrm{ml} / \mathrm{kg}$ hemorrhage in the anesthetized animals, as compared to $26 \pm 2 \mathrm{ml} / \mathrm{kg}$ in the conscious animals, indicating that anesthesia impairs circulatory control mechanisms responsible for maintaining pressure in hemorrhage (28). When hemorrhage was continued in the anesthetized animals to $26 \mathrm{ml} / \mathrm{kg}$, renal flow had fallen and renal resistance had risen substantially. This effect has been observed by others with equivalent levels of hemorrhage in anesthetized animals
$(19,20,22,24-27)$. In contrast, in the present study renal dilatation occurred uniformly in the normal conscious animals with similar degrees of hemorrhage. Renal dilatation can be observed in illustrations from previous studies measuring renal flow in response to hemorrhage in conscious animals; in the study by Gregg (29), during moderate hemorrhage when arterial pressure fell substantially, renal flow fell only slightly, indicating that a reduction in renal resistance had occurred, while in the study by Rushmer, Van Citters, and Franklin (30), illustrations showing a decrease in pressure but not renal flow with hemorrhage can also be observed. Thus in the conscious dog mild to moderate hemorrhage induced renal vasodilatation. This same mechanism is present in the anesthetized dogs, but appeared only during mild hemorrhage, less than $10 \mathrm{ml} / \mathrm{kg}$. Selkurt and Elpers also noted that renal flow was well maintained during mild hemorrhage in anesthetized dogs (27). Moreover, Kaihara, Rutherford, Schwentker, and Wagner observed an initial preservation of the renal bed with hemorrhage (31). Similarly, the investigation by Rector, Stein, Bay, Osgood, and Ferris indicated that little change occurred in total renal resistance with hemorrhage and that redistribution of renal blood flow occurred, with vasodilatation actually occurring in the inner cortex (32).

There are also difficulties with the use of intermittent methods of measuring renal blood flow during hemorrhage. For instance, the para-aminohippurate $(\mathrm{PAH})^{2}$ method of measuring renal flow during hemorrhage has been demonstrated to be inaccurate when compared with directly measured renal flow $(27,33-37)$; when compared with an electromagnetic flowmeter, the $\mathrm{PAH}$ method indicated an average of $30 \%$ lower flow during hemorrhagic hypotension (37). This discrepancy may be due to an accumulation of PAH in the kidney during hemorrhage and hyoptension, which may lead to underestimated renal blood flow measurements utilizing the PAH method (27) or because a redistribution of renal blood flow occurs within the kidney during hemorrhage $(24,32,38-40)$. Another difficulty with intermittent techniques, such as the $\mathrm{PAH}$ method or the microsphere method, is that intermediate responses will not be observed. For instance, the study by Forsyth, Hoffbrand, and Melmon did not note a fall in renal blood flow with $10 \%$ hemorrhage where mean arterial pressure did not fall (23). Moreover, with $30 \%$ hemorrhage, when mean arterial pressure had already fallen by $40 \mathrm{~mm} \mathrm{Hg}$, a significant increase in renal resistance was not noted. It is possible that if an intermediate point had been studied, renal vasodilatation might have been observed.

\footnotetext{
${ }^{2}$ Abbreviation used in this paper: $\mathrm{PAH}$, para-aminohippurate.
} 
Other reasons for the difference between the results of the present and of previous studies include the time of measurement, the severity of hemorrhage, and the presence of circulatory shock. If the hemorrhage is severe, prolonged, or results in shock, it is likely that renal vasoconstriction occurs, as was shown in the present study. In contrast, with relatively brief, mild, or moderate hemorrhage, leading to only a $20-30 \mathrm{~mm} \mathrm{Hg}$ reduction in arterial pressure, renal dilatation occurs. This concept is in accord with that of Folkow (41), suggesting that the neuron pool supplying the renal vessels has a higher threshold than those supplying muscle and gut. Thus, early vasoconstrictor responses to hemorrhage would occur in muscle and gut with relative sparing of the kidneys, as was actually observed in the present study.

Several sources of error were considered in the present study as well. It was possible that the Doppler flowmeter, which measures velocity, might falsely record an increase in velocity if vessel walls collapsed within the probe. However, it was observed that renal resistance generally declined even before arterial pressure fell, and during the renal dilatation identical techniques showed intense constriction in the systemic, mesenteric, and iliac beds. Furthermore, similar results were obtained with the electromagnetic flowmeter. Moreover, in the anesthetized dogs in this study and the conscious dogs after indomethacin pretreatment (Fig. 5), renal resistance did rise with moderate hemorrhage. Finally, when hemorrhage was continued after the sustained fall of 20-30 $\mathrm{mm} \mathrm{Hg}$ in the conscious dogs, renal dilatation was no longer observed; in the presence of severe hemorrhage $(50 \mathrm{ml} / \mathrm{kg})$, intense renal vasoconstriction was observed (Fig. 4). It was also considered that the canine spleen offers an unusual reserve mechanism, and accordingly studies were performed both before and after splenectomy. Similar results occurred in both cases, although less hemorrhage was required to reduce pressure to the same extent after splenectomy. Similarly, the baboons did not tolerate hemorrhage as well as the conscious dogs, which may be in part due to the absence of the splenic reservoir mechanism and also may be due to the presence of the dissociative agent, phencyclidine, which may disrupt circulatory control mechanisms as in general anesthesia.

The mechanism of the renal vasodilatation did not appear to be mediated by adrenergic, cholinergic, or histaminergic mechanisms, since after pretreatment with these blocking agents, singly or in combination, the renal bed still responded to hemorrhage with dilatation. However, after indomethacin, 4-6 mg/ $\mathrm{kg}$, a compound known to inhibit the synthesis of prostaglandin (42), the opposite response to hemorrhage resulted; i.e., substantial renal vasoconstriction occurred. This suggests that a prostaglandin-like compound is responsible for the renal dilatation with hemorrhage. In support of this concept, prostaglandins have been found in the kidney (43) and are thought to play a role in the regulation of renal vascular resistance (44). It has recently been shown that release of prostaglandin could in part be responsible for renal autoregulation (45). Thus, with arterial hypotension, prostaglandin release within the kidney could act to dilate the renal bed, thereby preserving renal flow at low pressures (45).

The relative sparing of the renal bed with low output and low pressure states, as suggested by Folkow (41) has also been observed in previous studies in conscious animals in our laboratory. When heart rate is drastically reduced abruptly in dogs with complete heart block, causing arterial pressure and cardiac output to fall, renal dilation occurs (46). When cardiac output is chronically reduced, as in congestive heart failure, intense mesenteric and iliac but not renal vasoconstriction occurs (47). Thus, the renal vascular bed responds to a variety of low output and low pressure states with less constriction and even dilatation, as in this case with acute hemorrhage.

The volume of hemorrhage required to produce a sustained $20-30 \mathrm{~mm} \mathrm{Hg}$ reduction in mean arterial pressure might be useful as an index of the circulation's ability to withstand hemorrhage. By this criterion, it is apparent that the intact normal conscious animal was best equipped to withstand hemorrhage and that blockade of cholinergic, beta adrenergic, and histaminergic receptors as well as of prostaglandin synthetase did not impair circulatory control substantially. On the other hand, splenectomy and, to a greater extent, alpha receptor blockade had greater effects in modifying the normal dog's capability to withstand hemorrhage. Hemorrhage was tolerated least well after anesthesia and laparotomy; an equivalent reduction in arterial pressure occurred in the anesthetized dogs with approximately onethird the amount of hemorrhage required in the conscious dogs.

In conclusion, in conscious dogs with all control mechanisms intact, the peripheral vascular adjustments to relatively rapid and moderate hemorrhage include modest constriction in the coronary bed and intense mesenteric and iliac vasoconstriction while the renal bed dilates. Renal dilatation after less severe hemorrhage also occurs in the intact, tranquilized primate. The renal dilatation, which can be classified as an autoregulatory response, appears to be due to prostaglandin release. With more severe hemorrhage, constriction occurs in the renal bed as well and can overcome the autoregulatory response.

\section{ACKNOWLEDGMENTS}

The technical assistance of T. Manders, the help in preparation of the manuscript from V. Fowler, and the generous

Renal Vasodilation with Hemorrhage 
supplies of propranolol from the Ayerst Laboratories, New York, and the phentolamine from the Ciba Pharmaceutical Co., Summit, N. J., are appreciated. The baboon experiments were conducted at the New England Regional Primate Center, Southboro, Mass. The encouragement and advice of Drs. E. Braunwald and A. C. Barger have been invaluable.

This work was supported in part by U. S. Public Health Service Grant HL-15416, NASA-Ames Research Grant 22036-001, and American Heart Association Grant 73883.

\section{REFERENCES}

1. Chien, S. 1967. Role of the sympathetic nervous system in hemorrhage. Physiol. Rev. 47: 214-288.

2. Haddy, F. J., H. W. Overbeck, and R. M. Daugherty, Jr. 1968. Peripheral vascular resistance. Annu. Rev. Med. 19: 167-194.

3. Vatner, S. F., and N. T. Smith. 1974. Effects of halothane on left ventricular function and distribution of regional blood flow and vasoactivity in dogs and primates. Circ. Res. 34 : 155-167.

4. Hershey, S. G., B. W. Zweifach, and E. A. Rovenstine. 1953. Effects of depth of anesthesia on behavior of peripheral vascular bed. Anesthesiology. 14: 245-254.

5. Vatner, S. F., D. Franklin, and E. Braunwald. 1971. Effects of anesthesia and sleep on circulatory response to carotid sinus nerve stimulation. Am. J. Physiol. 220: 1249-1255.

6. Vatner, S. F., C. B. Higgins, D. L. Franklin, and E. Braunwald. 1972. Extent of carotid sinus regulation of the myocardial contractile state in conscious dogs. $J$. Clin. Invest. 51 : 995-1008.

7. Franklin, D., N. W. Watson, K. Pierson, and R. L. Van Citters. 1966. A technique for radio telemetry of blood-flow velocity from unrestrained animals. Am. J. Med. Electron. 5: 24-28.

8. Vatner, S. F., D. Franklin, and R. L. Van Citters. 1970. Simultaneous comparison and calibration of the Doppler and electromagnetic flow meters. J. Appl. Physiol. 29: 907-910.

9. Snedecor, G. W., and W. G. Cochran. 1967. Statistical Methods. Iowa State University Press, Ames, Iowa. 6th edition. 91-98.

10. Hall, R. C., and R. L. Hodge. 1971. Changes in catecholamine and angiotensin levels in the cat and dog during hemorrhage. Am. J. Physiol. 221 : 1305-1309.

11. Darby, T. D., and D. T. Watts. 1964. Acidosis and blood epinephrine levels in hemorrhagic hypotension. Am. J. Physiol. 206 : 1281-1284.

12. Vander, A. J. 1967. Control of renin release. Physiol. Rev. 407 : 359-382.

13. Edwards, W. S., A. Siegel, and R. J. Bing. 1954. Studies on myocardial metabolism. III. Coronary blood flow, myocardial oxygen consumption and carbohydrate metabolism in experimental hemorrhagic shock. J. Clin. Invest. 33 : 1646-1661.

14. Entman, M. L., A. M. Martin, Jr., E. Mikat, J. H. T. Chang, and D. B. Hackel. 1968. Phasic myocardial blood flow in hemorrhage hypotension. Effect of beta sympathetic blockade. Am. J. Cardiol. 21: 881-885.

15. Hackel, D. B., and W. T. Goodale. 1955. Effects of hemorrhagic shock on the heart and circulation of intact dogs. Circulation. 11: 628-634.

16. Opdyke, D. F., and R. C. Foreman. 1947. A study of coronary flow under conditions of hemorrhagic hypotension and shock. Am. J. Physiol. 148: 726-739.

17. Granata, L., A. Huvos, A. Pasque, and D. E. Gregg. 1969. Left coronary hemodynamics during hemorrhagic hypotension and shock. Am. J. Physiol. 216: 1583-1589.

18. Lauson, H. D., S. E. Bradley, and A. Cournand. 1944. The renal circulation in shock. J. Clin. Invest. 23: 381402.

19. Abel, F. L., and Q. R. Murphy. 1962. Mesenteric, renal and iliac vascular resistance in dogs after hemorrhage. Am. J. Physiol. 202 : 978-980.

20. McGiff, J. C. 1964 . The renal vascular response to hemorrhage. J. Pharmacol. Exp. Ther. 145: 181-186.

21. Korner, P. I., G. S. Stokes, S. W. White, and J. P. Chalmers. 1967. Role of the automatic nervous system in the renal vasoconstriction response to hemorrhage in the rabbit. Circ. Res. 20: 676-685.

22. Pelletier, C. L., A. J. Edis, and J. T. Shepherd. 1971. Circulatory reflex from vagal afferents in response to hemorrhage in the dog. Circ. Res. 29: 626-634.

23. Forsyth, R. P., B. I. Hoffbrand, and K. L. Melmon 1970. Redistribution of cardiac output during hemorrhage in the unanesthetized monkey. Circ. Res. 27: 311319.

24. Carriere, S., G. D. Thornburn, C. C. C. O'Morchoe, and A. C. Barger. 1966. Intrarenal distribution of blood flow in dogs during hemorrhagic hypotension. Circ. Res. $19: 167-179$

25. Sapirstein, L. A., E. H. Sapirstein, and A. Bredemeyer. 1960. Effect of hemorrhage on the cardiac output and its distribution in the rat. Circ. Res. 8: 135-148.

26. Greenway, C. V., and A. E. Lawson. 1966. The effect of haemorrhage on venous return and regional blood flow in the anesthetized cat. J. Physiol. (Lond.). 184: $856-871$.

27. Selkurt, E. E., and M. J. Elpers. 1963. Influence of hemorrhagic shock on renal hemodynamics and osmolar clearance in the dog. Am. J. Physiol. 205: 147-152.

28. Chien, S. 1971. Hemodynamics in hemorrhage: influences of sympathetic nerves and pentobarbital anesthesia. Proc. Soc. Ex.p. Biol. Med. 136: 271-275.

29. Gregg, D. E. 1962. Hemodynamic factors in shock. In Shock: Pathogenesis and Therapy. K. D. Bock, editor. Springer-Verlag, Berlin, W. Germany. 50-60.

30. Rushmer, R. F., R. L. Van Citters, and D. L. Franklin. 1962. Shock: a semantic enigma. Circulation. 26: 445459.

31. Kaihara, S., R. B. Rutherford, E. P. Schwentker, and H. N. Wagner, Jr. 1969. Distribution of cardiac output in experimental hemorrhagic shock in dogs. J. Appl. Physiol. 27 : 218-222.

32. Rector, J. B., J. H. Stein, W. H. Bay, R. W. Osgood, and T. F. Ferris. 1972. Effect of hemorrhage and vasopressor agents on distribution of renal blood flow. $A m$. J. Physiol. 222 : 1125-1131.

33. Pappenheimer, J. R., and W. G. Kinter. 1956. Hematocrit ratio of blood within mammalian kidney and its significance for renal hemodynamics. Am. J. Physiol. $185: 377-390$.

34. Kinter, W. B., and J. R. Pappenheimer. 1956. Renal extraction of PAH and of Diodrast-I ${ }^{231}$ as a function of arterial red cell concentration. Am. J. Physiol. 185: 391-398.

35. Kinter, W. B., and J. R. Pappenheimer. 1956. Role of red blood corpuscles in regulation of renal blood flow and glomerular filtration rate. Am. J. Physiol. 185: 399-406. 
36. Selkurt, E. E. 1946. Comparison of renal clearances with direct renal blood flow under control conditions and following renal ischemia. Am. J. Physiol. 145: 376386.

37. Sykes, B. J., J. Hoie, and W. G. Schenk, Jr. 1972. An experimental study into the validity of clearance methods of measuring renal blood flow. Surg. Gynecol. Obst. 135: 877-882.

38. Grandchamp, A., R. Veyrat, E. Rosset, J. R. Scherrer and B. Truniger. 1971. Relationship between renin and intrarenal hemodynamics in hemorrhage hypotension. J. Clin. Invest. 50: 970-978.

39. Balint, P., J. Bartha, and A. Fekete. 1969. Haemorrhagic hypotension and intrarenal distribution of blood flow. Acta Physiol. Acad. Sci. Hung. 36: 13-26.

40. Nagy, A., P. Bencsath, K. Tornyai, and L. Vaslaki. 1971. Arteriovenous anastomoses in the kidney. VIII Intrarenal circulation during haemorrhagic hypotension. Acta Physiol. Acad. Sci. Hung. 39: 21-29.

41. Folkow, B. 1962. Nervous adjustments of the vascular bed with special reference to patterns of vasoconstrictor discharge. In Shock: Pathogenesis and Therapy. Springer-Verlag, W. Germany. 61-72.
42. Vane, J. K. 1971. Inhibition of prostaglandin synthesis as a mechanism of action of aspirin-like drugs. Nat. New Biol. 231 : 232-235.

43. McGiff, J. C., K. Crowshaw, N. A. Terragno, and A. J. Lonigro. 1970. Renal prostaglandins: possible regulators of the renal actions of pressor hormones. Nature. 227: 1255-1257.

44. McGiff, J. C., N. A. Terragno, K. U. Malik, and A. J. Lonigro. 1972. Release of a prostaglandin E-like substance from canine kidney by bradykinin: comparison with eledoisin. Circ. Res. 31: 36-43.

45. Herbaczynska-Cedro, K., and J. R. Vane. 1973. Contribution of intrarenal generation of prostaglandin to autoregulation of renal blood flow in the dog. Circ. Res. 33: $428-436$

46. White, S., T. Patrick, C. B. Higgins, S. F. Vatner, D. Franklin, and E. Braunwald. 1971. Effects of altering ventricular rate on blood flow distribution in conscious dogs. Am. J. Physiol. 221: 1402-1407.

47. Higgins, C. B., S. F. Vatner, D. Franklin, and E. Braunwald. 1974. Pattern of differential vasoconstriction in response to acute and chronic low-output states in the conscious dog. Cardiovasc. Res. 8: 92-98. 